\title{
Requalification of the river park: eco-houses in Elche
}

\author{
F. Pavoni, V. Echarri Iribarren, M. Aires Llinares, \\ A. B. García Molina \& C. Mora Hernández \\ Department of Building Construction. University of Alicante, Spain
}

\begin{abstract}
The city of Elche, the second most important town of Alicante's province, thanks to its 230,000 inhabitants, has a lot of heritage values such as the Misteri and the Palmeral. In its urban structure, the relation between the original urban plot and the modern one is made from the location of the river Vinalopò. Its canal is dry most of the year and its slopes are residual spaces that are not integrated with the modern and the ancient existing urban plot. The city of Elche relationship with the Palmeral does not give added value to the numerous urban parks that are in many parts of the city. This research could organize a new building typology of flats. It has tried to build a relationship with the environment that would bring benefits for the relationship between the urban plot and the river. In this way it would encourage a revitalization of the existing river park in support of architectural proposals such as an equipped park. In addition, these houses have bioclimatic technology of cooling evaporating using the natural airstream produced in the park which is induced through the building's structural system. Introduced by the chimney effect, the air is cooled by vegetal masses.

The orientation to the West of glazing, that looks at the river park, causes a lot of energy problems. This research analyses a wrapped and protective solar system based on a vertical rotating panel formed by low thickness and large format ceramic tiles in various sceneries. With modelling and the simulation through the software Design Builder, energetic demands for different sceneries are obtained which allow us to draw conclusions about the most efficient system in terms of energy consumption.
\end{abstract}

Keywords: energy efficiency, urban requalification, river park, porcelain stoneware. 


\section{Introduction}

A lot of cities are built behind the river that provides resources for living. Strategic or defensive reasons, in many cases, or for speculative ones in other cases, urban plots were projected by interest of organizational order, economic of infrastructures or the reasons of economic viability. Sometimes the rivers were improved to provide personality and quality urban space.

Recently, due to a growing concern for environmental issues related to the city, many cities [1] have restructured their urban plots or have transformed abandoned rivers' channels in a river park. This is the case in Pamplona. The river has become an attractive and functional element of the life of citizens providing a real discovery of nature, calm and playful activity.

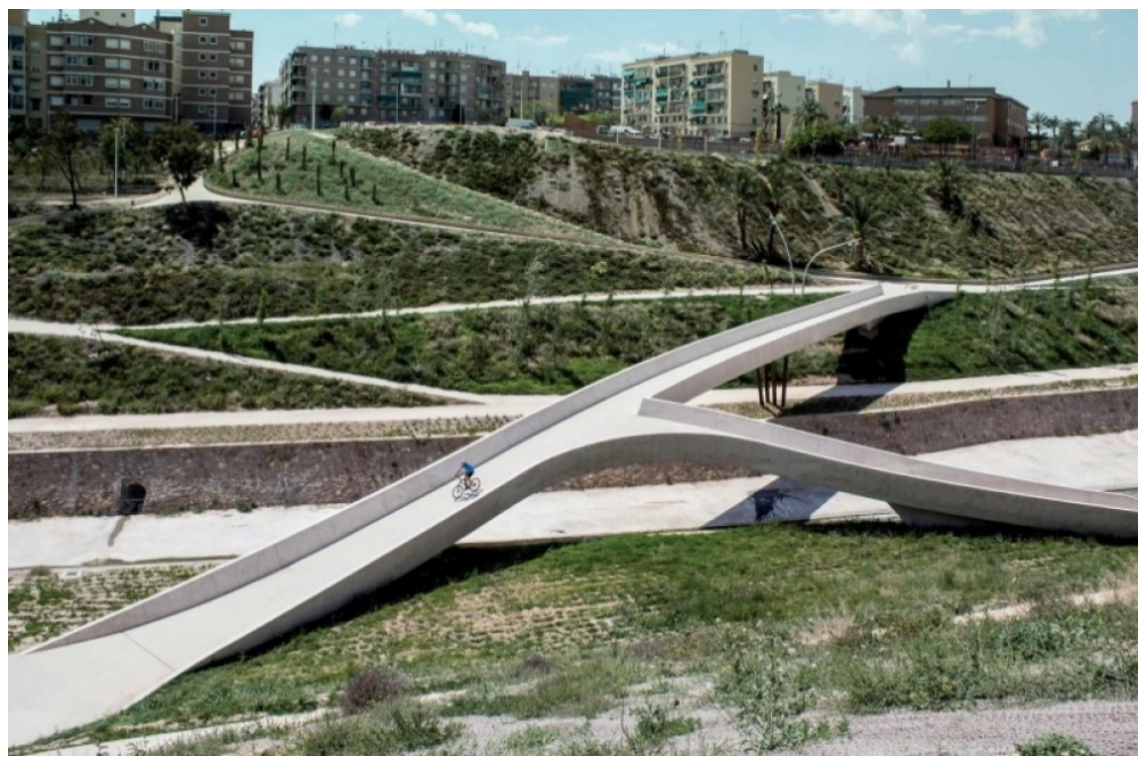

Figure 1: First phase of the river park of Elche.

In this context, an ideas competition held recently in Elche to reverse the trend of citizens' relationship with the river Vinalopò. The project of the river park, developed during its first phase, has created a new conception of the river as a vertebral column of activities in the city. The project has activated an urban regeneration process and the river started to be recognised as a fundamental place for the city.

In our opinion, this process also requires a reflection about the buildings' typologies along the river and generating a new landscape. A lot of residential buildings, that have ground floor more six plans, were build decades ago without considering the opportunity offered by the river's landscape [2].

This research analyses these existing buildings and their suitability for the new conception of the river Vinalopò and proposes design and energy efficiency 
strategies to make the city of Elche more harmonic with its natural surrounding and respectful to the environment, both for its smaller energetic consumptions and for its consequent reduction of $\mathrm{CO}_{2}$.

\section{Existing building back to the river}

Among the buildings that make up the edges of the river are those that raise from the level of the road without permeability toward the river's transit. Accessibility for pedestrians is compromise by this lack of permeability for more than forty meters and both for the excessive difference in height produced for the pedestrians' access to the river Vinalopò.

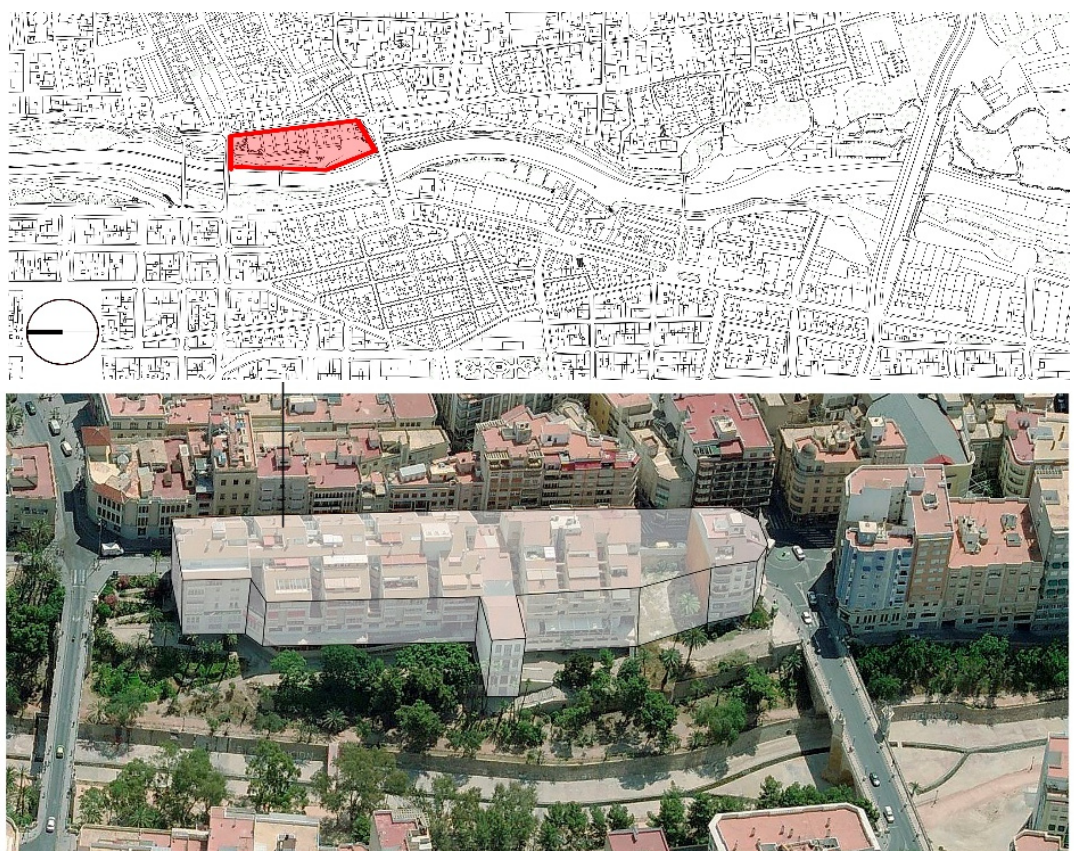

Figure 2: Existing building.

They offer the façade towards the street and the river with standard and repetitive glazing not giving sufficient consideration at the uniqueness to stay in front of the river or at the comfort and energy aspects derived from the excessive solar gains [3]. The absence of bioclimatic standards that support the passive airconditioning and the protection of the spaces versus the solar gains caused by the orientation to the West, making these buildings an architecture lacking in judgment, environmentally irresponsible and inappropriate for its location near the modern river park. Any of the block of flats could be replaced without causing any distortions. 


\section{Proposal for a new typology of the western bank of Vinalopò}

Once analysed the existing architecture, which is not appropriate as we can see, proposes a new building's typology which pursues the following requirements:

1. Facilitate the relationship and the accessibility to the current urban plot with the river park through the maximum permeability.

2. Diminish slope of the existing tracks generating a friendly park and facilitate the natural currents toward the inside of the building.

3. Sun protection through large-format ceramic pieces to regulate natural light and mitigate the solar gains' effects to the West.

4. Reduction of the energy demand of the buildings by passive systems as the solar protection, inclusion of plant masses and natural air current due to the chimney effect through inferior courtyard.

5. Uptake of photovoltaic energy at the roof.

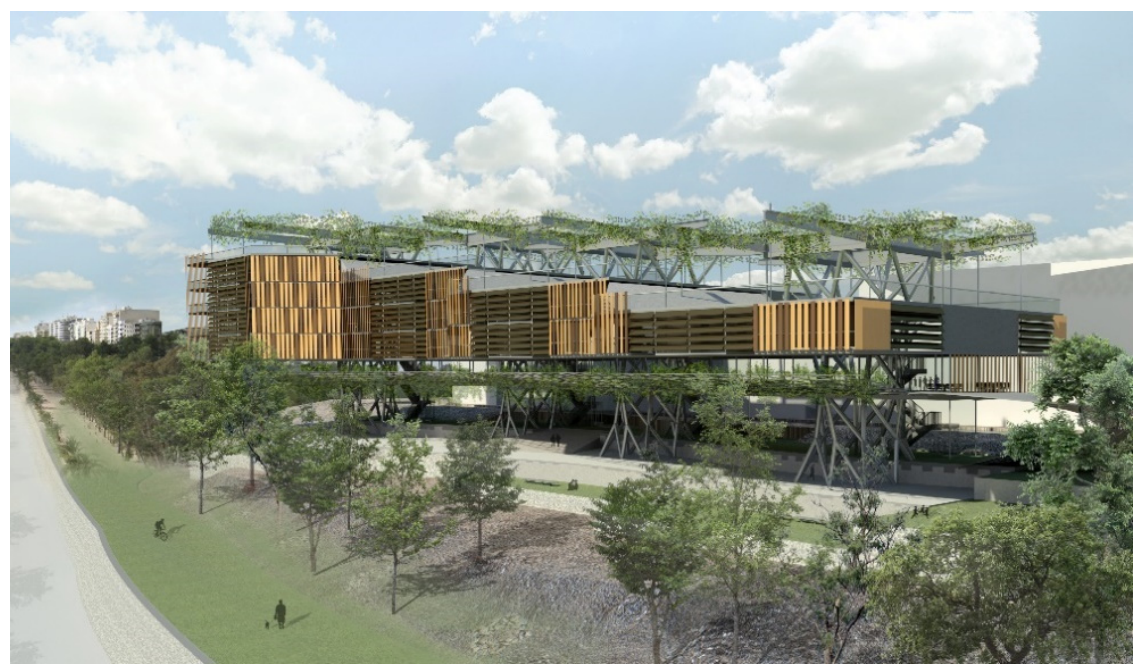

Figure 3: Render of the new building project.

The first objective is achieved through a singular structure system which releases the public space and which allows the patio's relationship with the river park. Through the chimney effect, there is passive conditioning depending on whether or not the users allow natural currents of air in their spaces. The typology of dwellings may have various configurations and, at the same time, maintain the previous premises.

Figure 3 shows one of them which has simulated to quantify the energy demands and its relationship with the energy demands of existing buildings. 


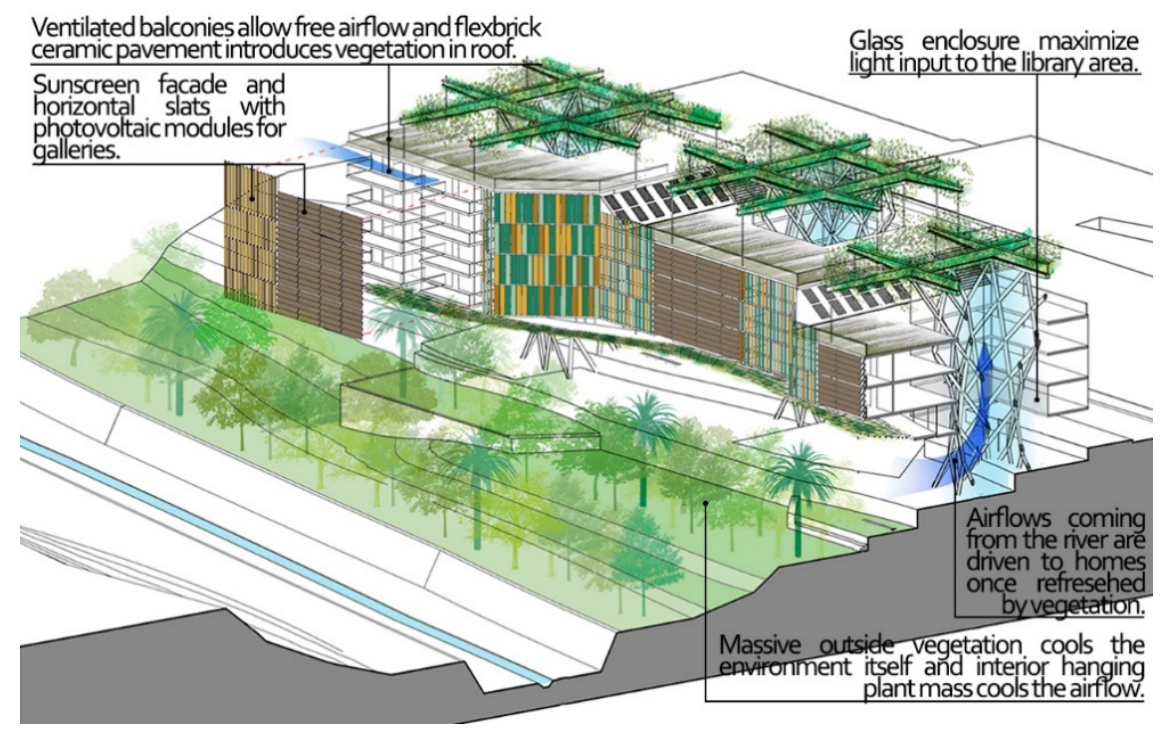

Figure 4: Study of the energy system project.

\section{Energy simulation with Design Builder}

Design Builder is a dynamic building energy analysis software. This is a threedimension graphical interface with which it is possible to represent any type of building to be analysed by defining the size, materials, heating and thermal loads. The calculation engine is Energy Plus [4]. The energy audit and the simulation below were done through the following phases:

- Geographical location and orientation;

- Construction of geometric model;

- Definition of enclosure model;

- Definition of parametres of the operating activities of building;

- Definition of installation;

- Simulation.

Through the climatic file ASHRAE/SWEC about ALICANTE-EL, the analysis is undertaken considering the real dynamic characteristics of the city. For Elche, summer is considered to be from 1 May to 30 November and winter from 1 December to 30 April. Even the definition of the orientation is fundamental: the orientation about the North define the correct contributions due to solar radiation.

The correct construction of geometric model is fundamental for the energy performance analysis and should be as close as possible to the real construction. To do this, the plans floor by floor are imported in the "layout" tab and it has recreated the perfect geometry of the opaque and transparent surfaces that make up the building envelope [5].

When the geometric model is completed, the next step is the definition of the materials that make up the opaque and transparent surfaces through the tab 
"construction". Design Builder has a database that provides all kinds of building components and through their combination it is possible to reproduce the stratigraphy of every surface in order to recreate the real thermal characteristics. This is critical because, for the determination of energy consumption of a building, thermal conductivity plays an important role.

The walls have the following stratigraphy and thermal transmittance:

- Gypsum plaster $-0.015 \mathrm{~m}$, and aerated brick $-0.07 \mathrm{~m}$;

- Isolation - variable thickness;

- Cement mortar - $0.01 \mathrm{~m}$;

- Brick - $0.115 \mathrm{~m}$;

- $\quad$ Gypsum plaster - $0.015 \mathrm{~m}$;

- Thermal transmittance - variable.

The roof has the following stratigraphy and thermal transmittance:

- $\quad$ Earth - $0.20 \mathrm{~m}$;

- $\mathrm{EPS}-0.08 \mathrm{~m}$;

- Inclinated screed $-0.07 \mathrm{~m}$;

- Reinforced cement- $0.30 \mathrm{~m}$;

- Gypsum plaster - $0.015 \mathrm{~m}$;

- Thermal transmittance $-\mathrm{U}=0.354 \frac{\mathrm{W}}{\mathrm{m}^{2} \mathrm{~K}}$

The transparent components of the building are defined through the tab "openings". In this case, the windows are consisting of double glazing $(6 \mathrm{~mm})$ with an Argon interspace $(13 \mathrm{~mm})$ and wood frame. The transmittance of the window is:

$$
\mathrm{U}=0.251 \frac{\mathrm{W}}{\mathrm{m}^{2} \mathrm{~K}} .
$$

To create an accurate analysis is built a very detailed calculation model that specifies the different temperature zones based on the use of the different locations in the tab "activity". The locals are divided into heated and unheated thermal zones. The heated zone includes all the rooms of the apartments and has the following characteristics for the new project:

- Volume of infiltration $=0.3 \frac{\mathrm{Vol}}{\mathrm{h}}$

- Volume of natural ventilation $=0.5 \frac{\mathrm{Vol}}{\mathrm{h}}$

While these are the values for the existing buildings:

- Volume of infiltration $=1 \frac{\mathrm{Vol}}{\mathrm{h}}$

- Volume of natural ventilation $=0.5 \frac{\mathrm{Vol}}{\mathrm{h}}$

These values are taken from the "Código técnico de la edificación" (CTE), which is the Spanish legislation regulating the energy efficiency of buildings. The indoor air temperatures (Ta) have been also established following the CTE, in particular the "Reglamento de Instalaciones Térmicas de los Edificio"s (RITE), which provides that operating temperatures of the spaces in a dwelling environment will be $20-23^{\circ} \mathrm{C}$ in winter and $23-25^{\circ} \mathrm{C}$ in summer. We have introduced in modelling Ta a set point of $21^{\circ} \mathrm{C}$ in winter and $24^{\circ} \mathrm{C}$ in summer [6]. 
The definition of installation is made from tab "HVAC". The installation chosen for the project is a "split or multi-split system with natural ventilation" both for cooling and for heating [7].

Figure 5 shows the Design Builder's model in plant and in axonometry.

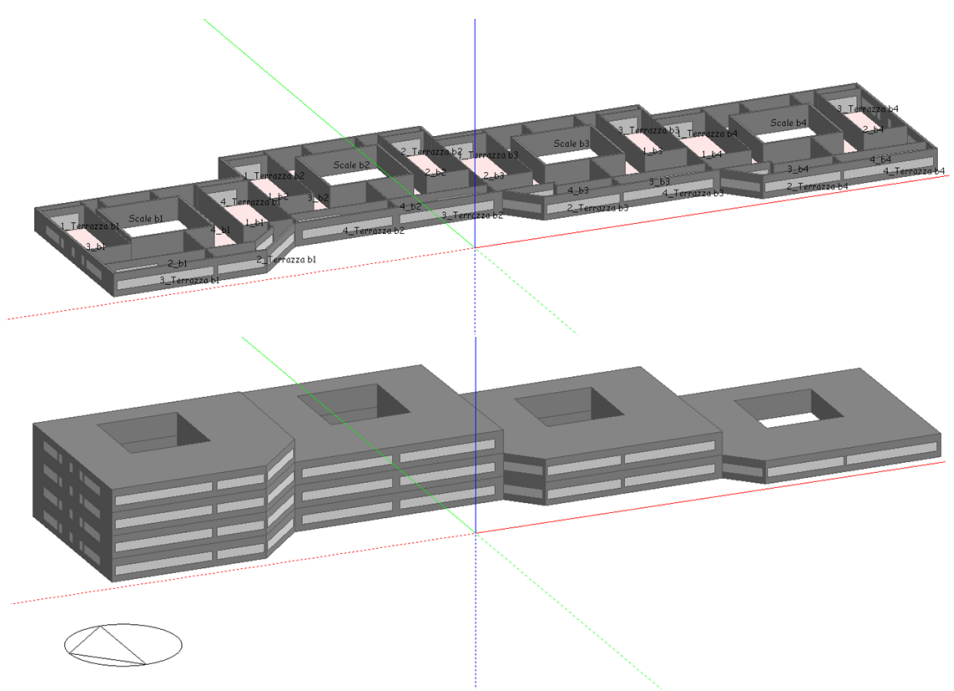

Figure 5: Design Builder's model.

Existing building
Scenery 1

Figure 6: Construction details of the sceneries. 
After the setting of the initial standards, the simulation can start. Simulations are relative to the existing building and the project with different types of interventions. There are three main groups called "Scenery 1", "Scenery 2"and "Scenery 3" and respectively represent a scenery without solar protection, with horizontal solar protection panels and the last with vertical solar protection panels. For each scenery, then are introduce the variables of the insulation's thickness (4$8-12 \mathrm{~cm})$ and panels' orientation $\left(30^{\circ}-45^{\circ}-90^{\circ}\right)$.

Table 1: $\quad$ Codes of sceneries.

\begin{tabular}{|c|c|c|c|c|c|c|}
\hline & & & $\begin{array}{l}\text { Existing } \\
\text { building }\end{array}$ & Scenery 1 & Scenery 2 & Scenery 3 \\
\hline \multirow{3}{*}{$\begin{array}{l}\text { Insulation } \\
\text { thickness }\end{array}$} & $4 \mathrm{~cm}$ & & & Sc1-4 & & \\
\hline & $8 \mathrm{~cm}$ & & & Sc1-8 & & \\
\hline & $12 \mathrm{~cm}$ & & & Sc1-12 & & \\
\hline \multirow{18}{*}{$\begin{array}{c}\text { Panels } \\
\text { inclination }\end{array}$} & \multirow{9}{*}{ Horizontal } & \multirow{3}{*}{$30^{\circ}$} & & & Sc2-30-4 & \\
\hline & & & & & Sc2-30-8 & \\
\hline & & & & & Sc2-30-12 & \\
\hline & & \multirow{3}{*}{$45^{\circ}$} & & & Sc2-45-4 & \\
\hline & & & & & Sc2-45-8 & \\
\hline & & & & & Sc2-45-12 & \\
\hline & & \multirow{3}{*}{$90^{\circ}$} & & & Sc2-90-4 & \\
\hline & & & & & Sc2-90-8 & \\
\hline & & & & & Sc2-90-12 & \\
\hline & \multirow{9}{*}{ Vertical } & \multirow{3}{*}{$30^{\circ}$} & & & & Sc3-30-4 \\
\hline & & & & & & Sc3-30-8 \\
\hline & & & & & & Sc3-30-12 \\
\hline & & \multirow{3}{*}{$45^{\circ}$} & & & & Sc3-45-4 \\
\hline & & & & & & Sc3-45-8 \\
\hline & & & & & & Sc3-45-12 \\
\hline & & \multirow{3}{*}{$90^{\circ}$} & & & & Sc3-90-4 \\
\hline & & & & & & Sc3-90-8 \\
\hline & & & & & & Sc3-90-12 \\
\hline
\end{tabular}

\section{Reduction of energy demand}

There are numerous standards that could be analysed to get a feedback of the river park in Elche and its relationship with the urban environment. In this research have decided to focus on the impact caused by new design of building envelopes to reduce energy consumption, subject of paramount importance according to the European directives [8]. To do this, as we have just seen, has decided to study the envelopes to the West, which typically represent a major thermal loads by solar gains. On a sunny day in the month of June, for example, between 18:00 and 21:00 hours solar gains through the glass are on the order of $500 \mathrm{~W} / \mathrm{m}^{2}$. Also increases significantly earnings by thermal transmittance when heated in excess the exterior 
surface of the opaque enclosures, being approximately $45^{\circ} \mathrm{C}$ in the monolayer of white and $70^{\circ} \mathrm{C}$ in the dark grey.

Figures 7 and 8 show the results obtained by simulation through Design Builder. All sceneries previously described have been considered with similar user conditions, as well as the hourly system activation multi-split HVAC to maintain the temperature settings. In this way the results of energy demands and consequent $\mathrm{CO}_{2}$ emissions could be compared to assess what envelopes would be suitable for the buildings that make up the edges of the river park. Firstly, it is significant to point out the deficit of the envelope of the existing building, by its high permeability to the passage of air infiltration that causes an increase of between $62 \%$ and $65 \%$ of the energy demand. That should add sceneries Sc2 and Sc3, that have a solar protective system, to involve reductions in energy demand between $17 \%$ and $44 \%$ against the Sc1 (Figure 7 ).

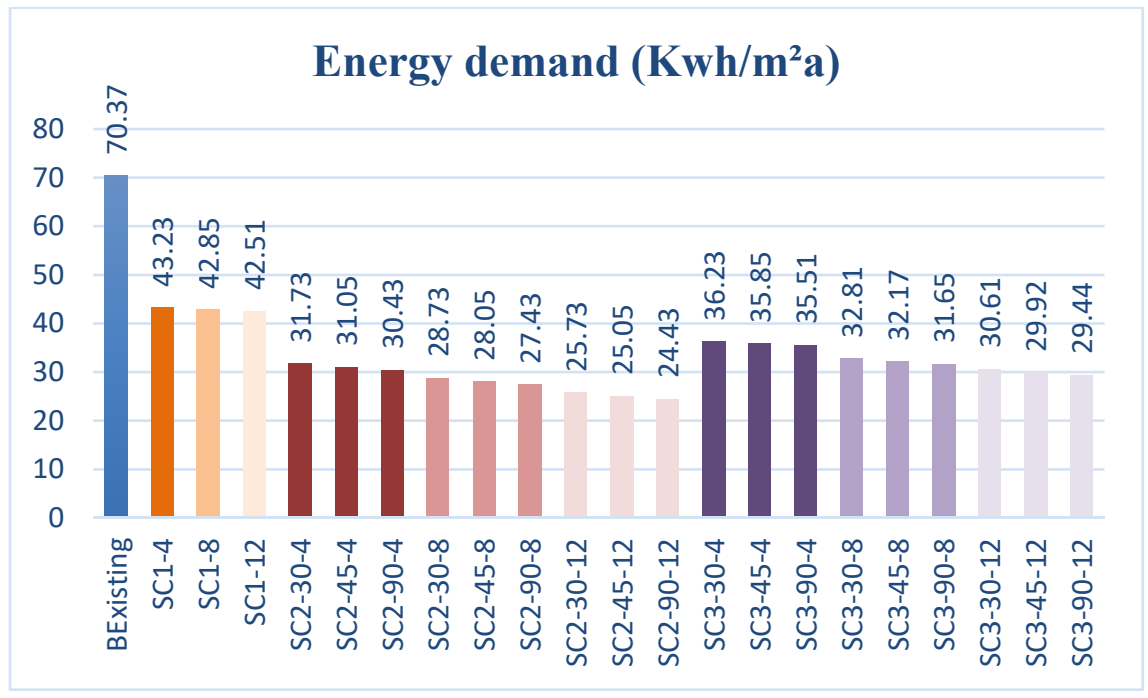

Figure 7: Graph of the energy demand.

With regard to the adoption of vertical or horizontal panels for sun protection, we see how in general the horizontal ones have better performance, leads to reductions in the energy demand around a 12 or $18 \%$ depending on the tilt of the slats. It is necessary to indicate that the use of cool air currents generated by the river park has been quantified in terms of reduction in energy demand. It is a complex issue [9], which essentially depends on the patterns of behaviour of the user and their tolerance to high speeds of the air in the interior of buildings [10]. The results obtained for sceneries 2 and 3 changing the insulation thickness of 4 , 8 and $12 \mathrm{~cm}$ demonstrates his little impact on energy demand and $\mathrm{CO}_{2}$ emissions. The decrease is in a range between $3.8 \%$ and $4 \%$ to reduce energy demand between the scenario with the isolation of $12 \mathrm{~cm}$ and $4 \mathrm{~cm}$. 


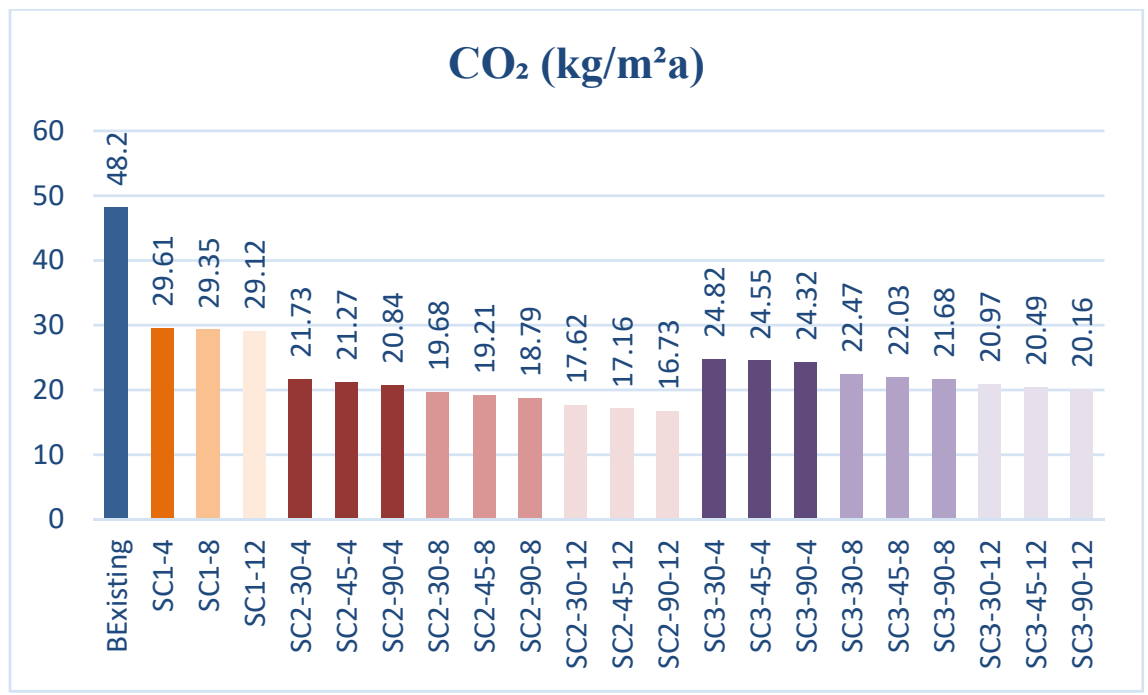

Figure 8: Graph of the $\mathrm{CO}_{2}$ consumption.

Some impact indicators were analysed, such as energy in the useful life of 25 years, both in $\mathrm{Sc} 1$ and $\mathrm{Sc} 2$, restoration and the structure of the stairs, enclosures, finishes and new air conditioning system and in the generation of construction and demolition waste (CDW). They concerned overall consumption of GER primary energy and GWP overall heating potential for the two scenarios [11], and in the case of air conditioning systems for the option of 4 heat pumps in the roof (Climate 1) and two heat pumps in the roof and two in the technical facilities floor (Climate 2). In order to quantify the emissions in the electrical mix, the ELCD database was taken into account, according to which production of $1 \mathrm{kWh}$ electricity gives off $0.41 \mathrm{kgCO}_{2}, 0.00122 \mathrm{kgCH}_{4}$ and $0.0000465 \mathrm{kgN}_{2} \mathrm{O}$ [12]. For conversion of final energy consumption at the user point to primary energy consumption and emissions, the provisional conversion factors published by IDAE for 2010 were taken into account, specifically $2.21 \mathrm{MWh}_{\mathrm{p}} / \mathrm{MWh}_{\mathrm{f}}$ and 0.27 $\mathrm{tCO}_{2} \mathrm{eq} / \mathrm{MWh}$ respectively. In all the scenarios proposed, efforts were made to reduce the energy demand and $\mathrm{CO}_{2}$ emissions (Figure 8).

\section{Conclusions}

The revitalization of the channels of the rivers in many of our cities is a crucial issue for a sustainable urban development. In many cases, these are areas of opportunity to improve the quality of life of citizens and the protection of the environment. The relationship between the existing architecture, residential buildings' typology, and urban development are decisive for such revitalization. In the case study, the city of Elche, the implementation of the first phase of the river park is backed by the importance to give a new image of the city. It has gained new life, with a greater number of visitors and citizens who use it as a playful space. 
However, the existing buildings' typology hinders the relationship between the citizens and the river. In this research it is proposed a new building's typology that greatly increases the permeability of the flows of persons, in soft-stepping toward the River, with the release of much of the floor space. Also has sought a zero power consumption building by adopting system cover assets, passive cooling through vegetal masses and the reduction of the energy demand through skins equipped with adequate protection against solar radiation of West.

It has simulated the thermal behaviour of the envelopes of the new building, with different protection of glazing systems, horizontal and vertical panels with different inclinations. Through the Design Builder have been obtained energy demands by simulation of three different scenarios, with different panels inclinations and different thickness of thermal insulation $(4,8$ and $12 \mathrm{~cm})$. Regarding the existing building, there is a reduction of the energy demand between $62 \%$ and $65 \%$, mainly due to the drastic reduction of air infiltration by the sealing of the envelope. When there is not solar protection ( $\mathrm{Sc} 1)$, energy demand rises between 17 and 44\% against Sc2 and Sc3. The heat load from solar gain without protection has been quantified in $20.02 \mathrm{kWh} / \mathrm{m}^{2} \mathrm{a}$. With regard to the adoption of vertical or horizontal panels for sun protection, have better performance the horizontal, with reductions of energy demand around $12 \%$ or $18 \%$ depending on the tilt of the slats. The results obtained for sceneries 2 and 3 changing the insulation thickness of 4,8 and $12 \mathrm{~cm}$ demonstrates his little impact on energy demand and $\mathrm{CO}_{2}$ emissions. The decrease is in a range between $3.8 \%$ and $4 \%$ to reduce energy demand between the scenery with the isolation of $12 \mathrm{~cm}$ and $4 \mathrm{~cm}$.

\section{References}

[1] Rogers, R.; Gumuchdjian, Philip. Cities for a small planet. Faber \& Faber Limited, London, 1997, p. 3.

[2] Cuchí, Albert. Las Claves de la Sostenibilidad, en SOLANAS, Toni (coord.). Vivienda y Sostenibilidad en España, vol. I. Gustavo Gili. Barcelona, 2007, pp. 19-20.

[3] Yeang, Ken. Ecodesign. A Manual for Ecological Design. John Wiley \& Sons, Ltd. London, 2006, p. 415.

[4] Zhenjun M.; Cooper P.; Daly D.; Ledo L. "Existing building retrofits: methodology and state-of-the-art", Energy and Buildings, Volume 55, December 2012, pp. 889-902.

[5] Van Gelder L.; Janssen H.; Roels S. "Probabilistic design and analysis of building performances: Methodology and application example", Energy and Buildings, Volume 79, August 2014, pp. 202-211.

[6] Marino C.; Minichiello F.; Bahnfleth W. "The influence of surface finishes on the energy demand of HVAC systems for existing buildings", Energy and Buildings, Volume 95, May 2015, pp. 70-79.

[7] Directive 2010/31/EU. European Parliament and of the council of 19 May 2010 on the energy performance of buildings. Available online: http/eurlex.europa.eu/LexUriServ//LexUriServ.do?uri=OJ:L:2010:153:0013:0035: EN:PDF. 
[8] UNE-EN 15459:2008. Eficiencia energética de los edificios. Procedimientos de evaluación económica de los sistemas energéticos de los edificios. Madrid: AENOR, 2008.

[9] Assiego, R., Calleja, G., Cejudo, J.M. et al. A decision-making LCA for energy refurbishment of buildings. Conditions of comfort. Energy and Buildings, 70: 333-342. 2014.

[10] ELCD Database, www.eplca.jcr.ec.europa.eu/ELCD3/index.xhtml;jsession $\mathrm{id}=9$ FC03F3B6A0A5F8252F667E462DF467C

[11] Miguel Angel Padilla-Marcos, Jesús Feijó-Muñoz and Alberto Meiss. Wind velocity effects on the quality and efficiency of ventilation in the modelling of outdoor spaces. Case studies. Journal of Building Services Engineering Research \& Technology, 2015, 37, 33-50. DOI: 10.1177/ 0143624415596441

[12] Roger Harrison; Michael Spearpoint. A comparison between channelled and unchannelled balcony spill plumes, Journal of Building Services Engineering Research \& Technology, 31, 3 (2010) pp. 265-277. 